\title{
Quaderni
}

QUADERNI Communication, technologies, pouvoir

81 | Printemps 2013

L'humain médicament

\section{Paul Bacot. Les mots des élections}

Jessica Sainty

\section{OpenEdition}

Journals

Édition électronique

URL : http://journals.openedition.org/quaderni/724

DOI : 10.4000/quaderni.724

ISSN : 2105-2956

\section{Éditeur}

Les éditions de la Maison des sciences de l'Homme

Édition imprimée

Date de publication : 5 juin 2013

Pagination : 113-115

\section{Référence électronique}

Jessica Sainty, "Paul Bacot. Les mots des élections », Quaderni [En ligne], 81 | Printemps 2013, mis en ligne le 05 mai 2013, consulté le 25 septembre 2020. URL : http://journals.openedition.org/quaderni/ 724 ; DOI : https://doi.org/10.4000/quaderni.724 


\section{Compte rendu}

\section{Les mots des élections}

\section{Paul Bacot}

Les presses universitaires du Mirail, Toulouse, 2012

par Jessica Sainty

PACTE - IEP de Grenoble

Les mots des élections, paru au printemps 2012, dans la collection « Les mots de » des Presses universitaires du Mirail et rédigé par Paul Bacot - professeur de science politique à l'IEP de Lyon et spécialiste de politologie lexicale -, a comme objectif affiché de proposer un abécédaire permettant de décrypter les élections « en général », même si les élections présidentielles et législatives constituent le cœur de l'analyse. Autour de l'abécédaire figurent quelques compléments essentiels à la lecture et à la compréhension des mots et expressions sélectionnés, notamment une utile chronologie des dates importantes de l'institutionnalisation des élections pour la France, l'Europe et le monde, ainsi qu'une « bibliographie récente » située en fin d'ouvrage, qui comprend une douzaine de références la plupart incontournables pour l'analyse du fait électoral, et dresse un panorama des différentes tendances et courants traversant la sociologie politique et électorale française.

L'avant-propos revient sur la définition retenue des élections dans le cadre de cet abécédaire : celles-ci sont entendues avant tout comme l'expression de la concurrence pour le pouvoir que se livrent les forces politiques dans les systèmes politiques pluralistes. Si cette concurrence est omniprésente lors des élections, moments-clés de la compétition politique, elle ne disparaît pas toutefois avec la clôture du scrutin et la proclamation des résultats. Ainsi, « les mots des élections » sont autant ceux du déroulement du scrutin et de son encadrement, que ceux de la vie politique ou de l'actualité médiatique. De plus, ces mots ne sont pas monopolisés par une seule catégorie d'acteur, mais sont ceux de plusieurs groupes : élus et candidats, analystes, citoyens et électeurs. 
Le choix des mots et expressions sélectionnés dans l'abécédaire souligne clairement la volonté de l'auteur d'ancrer l'ouvrage dans l'actualité de la vie politique, française la très grande majorité du temps, en couvrant aussi bien les discours académiques, médiatiques ou encore " populaires » sur les enjeux, échéances et comportements électoraux. Ainsi, se trouvent dans l'abécédaire les définitions des mots « ballotage», « mode » ou « panneau », qui apportent des éléments de connaissance précis autour du déroulement des élections, en revenant sur leurs manifestations les plus visibles que peuvent rencontrer les électeurs dans l'espace public ou dans le discours médiatique. De façon complémentaire, d'autres notices, comme « boycott », « charcutage ", " pêche » ou " vingt-et-un avril », s'attardent sur des expressions plus ancrées dans l'actualité politique récente, permettant ainsi aux électeurs d'aujourd'hui de s'approprier réellement le sens de formules qui peuvent apparaître comme galvaudées.

Paul Bacot revient plusieurs fois sur la tendance forte à la "prédiction» dans le commentaire électoral produit à la fois par les médias, mais aussi - trop souvent ? - par les politologues. Cette tendance s'appuyant sur le commentaire des sondages pré-électoraux, l'auteur rappelle que ces derniers ne sont que des « photographies » de l'opinion à un moment précis et insiste sur leur faible fiabilité prédictive. Toutefois, il est regrettable que les différentes analyses des comportements électoraux présentés fassent la part trop belle aux études quantitatives (cf. les notices « échantillon », « géographie » ou encore « sondage »). La disqualification de la géographie électorale au vu du risque - bien que réel et vérifié à plusieurs reprises - de fallace écologique, c'est-à-dire d'une erreur d'interprétation statistique où le comportement d'un groupe est affecté sans distinction à tous les individus qui le composent, rend bien peu justice à un certain nombre de travaux récents en science politique comme en géographie, qui cherchent à renouveler les approches spatialisées des comportements électoraux par la prise en compte des contextes sociaux ou locaux. De la même façon, affirmer que les sondages ont pris le pas sur les autres techniques d'enquête en matière de comportements politiques, du fait de l'importance que leur accorderaient partis politiques (dans la conduite des campagnes) et électeurs (dans leur choix électoral), revient à largement surestimer l'influence des sondages - ou à largement sous-estimer les compétences politiques des électeurs - mais aussi à laisser de côté les travaux fondés sur des enquêtes qualitatives, ou mêlant plusieurs techniques, des comportements électoraux, qui sont fréquents depuis 
le milieu des années 1990.

En conclusion, si l'ouvrage nous semble s'adresser avant tout plutôt à un public élargi qu'à un public plus averti, il n'en reste pas moins que l'humour régulièrement employé dans cet abécédaire, tant pour le choix des mots ou expressions que pour leurs définitions, ponctue la lecture d'agréables moments - par exemple, la définition de « suppléante » qui insiste sur le caractère genré (et tacite) de la répartition des rôles politiques. 
